\title{
Unstable Representation of Sound: A Biological Marker of Dyslexia
}

\author{
Jane Hornickel ${ }^{1}$ and Nina Kraus ${ }^{1,2,3}$ \\ ${ }^{1}$ Auditory Neuroscience Laboratory, Department of Communication Sciences and Disorders, and ${ }^{2}$ Department of Neurobiology and Physiology, \\ Northwestern University, Evanston, Illinois 60208, and ${ }^{3}$ Department of Otolaryngology, Northwestern University, Chicago, Illinois 60611
}

Learning to read proceeds smoothly for most children, yet others struggle to translate verbal language into its written form. Poor readers often have a host of auditory, linguistic, and attention deficits, including abnormal neural representation of speech and inconsistent performance on psychoacoustic tasks. We hypothesize that this constellation of deficits associated with reading disorders arises from the human auditory system failing to respond to sound in a consistent manner, and that this inconsistency impinges upon the ability to relate phonology and orthography during reading. In support of this hypothesis, we show that poor readers have significantly more variable auditory brainstem responses to speech than do good readers, independent of resting neurophysiological noise levels. Thus, neural variability may be an underlying biological contributor to well established behavioral and neural deficits found in poor readers.

\section{Introduction}

As infants, we learn language from analyzing the properties of our acoustic environment (Saffran et al., 1996). This process depends on the nervous system's ability to access and respond to sound in a faithful and consistent manner. When input to the auditory system is not coherent from one instance to the next, this can interrupt the ability to link sound to meaning and impede language development (Friel-Patti and Finitzo, 1990). We hypothesize that stable neural representation of sound supports the sound-to-meaning connections crucial for the development of language and reading skills. Children with dyslexia, who often exhibit impairments in auditory-based perceptual skills and auditory neurophysiology, may suffer from variable interactions with sound. Behavioral manifestations of auditory impairments in dyslexia include impaired perception of speech in background noise (Bradlow et al., 2003; Ziegler et al., 2009), speech discrimination (Bogliotti et al., 2008), rhythm perception (Goswami et al., 2011; Huss et al., 2011), temporal processing (Van Ingelghem et al., 2001; Cohen-Mimran and Sapir, 2007), and difficulty directing and switching auditory attention (Hari and Renvall, 2001; Facoetti et al., 2010; Lallier et al., 2010). Neurophysiological abnormalities include delayed and harmonically impoverished responses from the auditory brainstem (Banai et al., 2009; Basu et

\footnotetext{
Received Sept. 2, 2012; revised Dec. 13, 2012; accepted Jan. 11, 2013.

Author contributions: J.H. and N.K. designed research; J.H. performed research; J.H. contributed unpublished reagents/analytic tools; J.H. analyzed data; J.H. and N.K. wrote the paper.

This work was supported by National Institutes of Health Grant R01DC01510, the Hugh Knowles Center of Northwestern University, and an Interdisciplinary Research Fellowship from the Northwestern University Cognitive Science program. We thank Erika Skoe, Trent Nicol, and Samira Anderson for their review of the manuscript; the members of the Auditory Neuroscience Laboratory for their assistance with data collection; and the children and their families for participating.

The authors declare no conflicts of interest, financial or otherwise.

Correspondence should be addressed to Nina Kraus, 2240 Campus Drive, Evanston, IL 60208. E-mail: nkraus@northwestern.edu.

DOI:10.1523/JNEUROSCI.4205-12.2013

Copyright $\odot 2013$ the authors $\quad 0270-6474 / 13 / 333500-05 \$ 15.00 / 0$
}

al., 2010; Hornickel et al., 2011; Hornickel et al., 2012b), reduced subcortical and cortical representation of stimulus differences (Banai et al., 2005; Hornickel et al., 2009; Noordenbos et al., 2012), and atypical cortical activity in the auditory and reading networks (Kraus et al., 1996; Pugh et al., 2001; Wible et al., 2002; Abrams et al., 2006; Cao et al., 2006; Bonte et al., 2007; Gou et al., 2011), which can be predictive of later reading ability when assessed in young children (for review, see Gabrieli, 2009). This constellation of behavioral and neurophysiological deficits combine, resulting in impaired perception of speech that can adversely affect reading acquisition. We hypothesize that an inconsistency of the auditory nervous system in responding to sound may contribute to poor auditory processing and reading impairments in children. To investigate this, we assessed the consistency of auditory brainstem responses across a recording session by measuring brainstem responses to speech syllables from normal hearing children ages $6-13$ years with a wide range of reading abilities. We predicted, and found, that children who are poor readers have more variable auditory responses than good readers.

\section{Materials and Methods}

\section{Participants}

One hundred children (age range, 6-13 years; mean age, 9.7 years; 42 girls) participated. All had normal hearing, passing a hearing screening at a $20 \mathrm{~dB}$ hearing level (air conduction) for octaves from 250 to $8000 \mathrm{~Hz}$; normal click-evoked brainstem responses when compared with laboratory norms; no neurological disorders; and a performance IQ $>75$ (Woerner and Overstreet, 1999). Based on the approximately trimodal distribution of performance on a measure of oral word reading fluency (Test of Oral Word Reading Efficiency, Sight subtest; Torgesen et al., 1999), children were divided into the following three groups: good readers $(>120 ; n=34)$; average readers $(95-105 ; n=34)$; and poor readers $(<90 ; n=32)$. Scores for the average readers straddled the mean, whereas the good and poor readers performed $\sim 1$ SD above and below the mean, respectively. Participants' diagnoses (if applicable), family socioeconomic status (as assessed by mother's education), and attention 

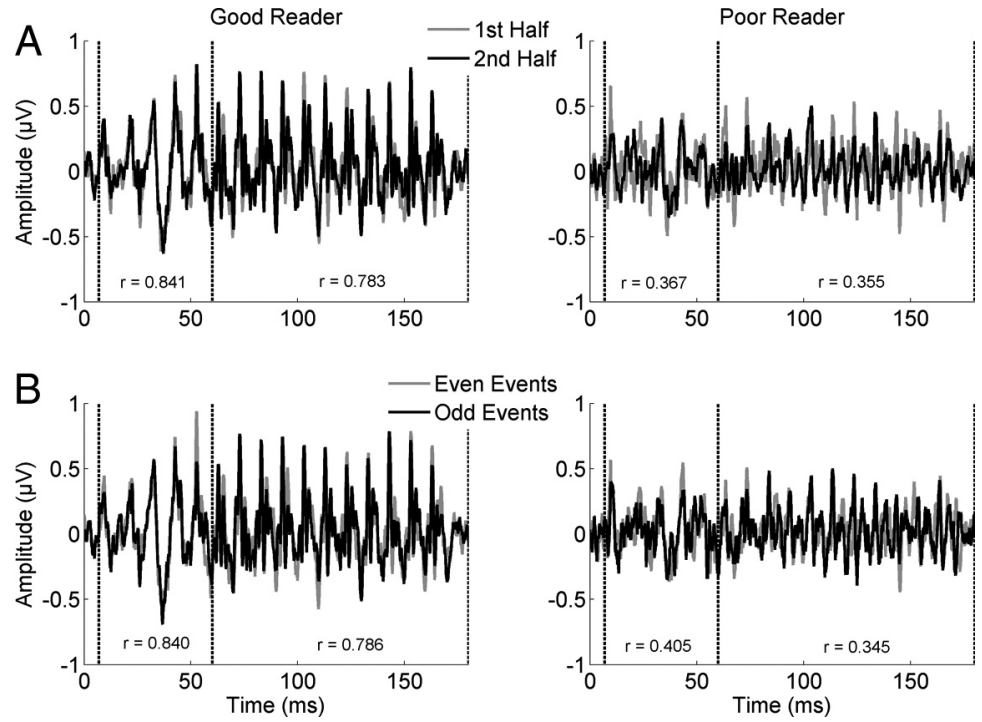

Figure 1. Auditory brainstem responses of poor readers are more variable than those of good readers. Responses from a representative good reader (left) and poor reader (right) are plotted to illustrate the increased variability in the poor readers relative to good readers. $\boldsymbol{A}, \boldsymbol{B}$, The response analyses regions are marked by dashed lines. Poor readers have more variable responses (lower $r$ values) than good readers when calculating consistency between the first half of the recording and the second half $(\boldsymbol{A})$ or between the even events and the odd events $(\boldsymbol{B})$. Groups did not differ in the overall magnitude or prestimulus magnitude of the response.

skills were collected from a parental report via a laboratory internal demographic survey and the ADHD Rating Scale IV (DuPaul et al., 1998). Twenty-eight of the poor readers had an external diagnosis of a reading impairment, and 13 of those children additionally had diagnoses of attention impairments; however, parent ratings of attention abilities were not predictive of the physiologic measures (see greater detail in Results). All procedures were approved by the Internal Review Board at Northwestern University, and parents and children gave their informed consent and assent, respectively.

\section{Stimuli}

Stimuli were $170 \mathrm{~ms}$ [ba] and [ga] syllables created using a Klatt-based synthesizer (Klatt, 1980). Both stimuli had a $50 \mathrm{~ms}$ formant transition in which the first, second, and third formants were dynamic, and stable fundamental frequency, fourth formant, and fifth formant for their duration. See Hornickel et al. (2009) for additional stimulus details. Stimuli were presented at $80 \mathrm{~dB}$ SPL in alternating polarities monaurally to the right ear through insert earphones (ER-3, Etymotic Research).

\section{Neurophysiological data recording and reduction}

Auditory brainstem responses were collected using a vertical montage (active $\mathrm{Cz}$, forehead ground, ipsilateral earlobe reference) using $\mathrm{Ag}-\mathrm{AgCl}$ electrodes with impedances $<5 \mathrm{k} \Omega$. A total of 6000 artifact-free responses (3000 for each polarity) were obtained for each sound. During the recording, children sat quietly watching a movie and heard the soundtrack in their unoccluded left ear presented at $\sim 40 \mathrm{~dB}$ SPL. Movie watching encouraged compliance during the passive recordings.

Data were pooled across two studies, which used slightly different presentation and collection equipment and methods. For 64 of the participants (18 good readers, 18 average readers, and 28 poor readers), the two stimuli were presented intermixed with six other speech sounds by the Compumedics NeuroScan Stim ${ }^{2}$ presentation software at a rate of 4.35 stimuli/s (Hz). Responses were collected in Compumedics NeuroScan Acquire, digitized at 20,000 Hz, and off-line bandpass filtered from 70 to $2000 \mathrm{~Hz}$ (12 dB/octave roll off). For 36 participants (16 good readers, 16 average readers, and 4 poor readers), stimuli were presented and responses were recorded with SmartEP using the cABR module (Intelligent Hearing Systems). The two stimuli were presented in alternating blocks at a rate of $4.35 \mathrm{~Hz}$, and responses were digitized at $13,333 \mathrm{~Hz}$ and on-line bandpass filtered from 50 to $3000 \mathrm{~Hz}(6 \mathrm{~dB} /$ octave roll off).
In both recording systems, responses were epoched into $230 \mathrm{~ms}$ windows ( $40 \mathrm{~ms}$ of prestimulus activity), and responses greater than $\pm 35 \mu \mathrm{V}$ were rejected as artifact.

\section{Data analyses}

Response consistency. Consistency of the auditory brainstem response over time was computed by comparing response subaverages from the first and last halves of the recording (3000 events each). Comparisons were made by correlating the two subaverage waveforms, with $r$ values closer to 1 representing more morphologically coherent subaverages. For the data collected with the Compumedics NeuroScan Acquire system $(n=64)$, a second analysis technique was used in which an average of the 3000 evennumbered events was compared with an average of the 3000 odd events Correlations between the two analysis techniques were high (formant transition: $r=0.800$; vowel: $r=0.882$ ), and we suggest that they are reliably reflecting the same underlying mechanism of variability present throughout the recording. The even-odd analysis was not possible for the data collected on the Intelligent Hearing Systems SmartEP system because of how the data are recorded and exported.

Response consistency calculations were made separately for the portions of the response reflecting the formant transition $(7-60 \mathrm{~ms})$ and the steady-state vowel (60-180 ms). For statistical analyses, response consistency was collapsed across the two stimuli to form one metric. All data were Fisher transformed before statistical analyses; in Figures 1 and 2, and Table 1, response consistency values are reported as $r$ values. See Hornickel et al. (2012a) for additional details.

To confirm that we could collapse data from the two recording systems, we compared children from the two studies pooled across the good and average reader groups and found no significant differences between the recording systems in response consistency values for the formant transition (Compumedics NeuroScan system: $r=0.657$; Intelligent Hearing Systems system: $\left.r=0.667 ; t_{(66)}=-0.299, p>0.766\right)$ or vowel portions of the responses (Compumedics NeuroScan system: $r=0.678$; Intelligent Hearing Systems system: $r=0.693 ; t_{(66)}=-0.467, p>$ 0.642 ). The poor reader group was excluded from this analysis due to a disproportionate number of children in that group participating in the study using the Compumedics NeuroScan system ( 28 of 32 children).

Additionally, response consistency was calculated as the correlation between the click-evoked brainstem responses collected at the start and at the end of the recording session (3000 sweeps each). Due to data recording errors, click response files were missing for four children (three good readers and one poor reader).

Baseline neurophysiological activity and response amplitude. Baseline neurophysiological activity was measured as the root mean square (RMS) amplitude of the response $40 \mathrm{~ms}$ time window preceding each sound presentation $(-40-0 \mathrm{~ms})$ and for the entire response window $(0-180$ $\mathrm{ms}$ ). As with response consistency, data from responses to the two stimuli were averaged together. Because prestimulus amplitude was collected in the absence of the evoking sound, it was thought to reflect resting neurophysiological activity or neurophysiological noise.

\section{Statistical analyses}

As IQ was marginally correlated with response consistency across the group, a multivariate analysis of covariance (ANCOVA) was used to determine whether group differences existed for response variability (both time ranges), prestimulus RMS, and response RMS. Follow-up independent $t$ tests were conducted when appropriate, and Mann-Whitney $U$ tests were used for the even/odd comparison due to unequal group sizes. Paired $t$ tests were used to compare response consistency in the 
formant and vowel regions within individuals. Statistical analyses were performed in SPSS (IBM), and outliers greater than \pm 2 SDs were corrected to exactly \pm 2 SDs.

\section{Results}

As predicted, there was a main effect of reading group for consistency of the brainstem response to speech in the formant transition (Multivariate ANCOVA, $\left.F_{(2,92)}=6.14, p=0.003\right)$ with a trending effect for the vowel response $\left(F_{(2,92)}=\right.$ $2.86, p=0.062$ ), but not for neurophysiological noise (prestimulus amplitude), the overall amplitude of the response, or the consistency of the brainstem response to clicks $\left(F_{(2,92)}=0.86, p>0.425 ; F_{(2,92)}\right.$ $=2.18, p>0.115 ; F_{(2,92)}=1.74, p>$ 0.180 , respectively). Post hoc tests indicated that poor readers had more variable brainstem responses to speech than did good readers (formant transition: $p=$ 0.002; vowel: $p=0.038$ ) and that they were marginally worse than the average readers in the formant transition portion (formant transition: $p=0.055$; Table 1 ; Figs. 1, 2). Within the poor reader group, variability in the formant transition region was greater than in the vowel portion of the response $\left(t_{(31)}=-2.18, p=0.037\right)$, an effect that was marginal for the average readers $\left(t_{(33)}=-1.88, p=0.069\right)$ and absent for the good readers $\left(t_{(33)}=-1.08, p>0.250\right)$.

The mechanisms responsible for increased response variability include fatigue over the course of the experiment and/or intertrial variability (Fig. 2). For a subset of the subjects $(n=64)$, response variability was also computed for averages reflecting every other sweep. This approach revealed the same deficits in response consistency for poor $(n=29)$ relative to good readers $(n=18$; formant transition: Mann-Whitney $U$ test, $-2.88, p=$ 0.004; vowel: Mann-Whitney $U$ test, $-2.11, p=0.035)$ that were seen for the first-last analysis, including marginal deficits for poor readers relative to average readers in the formant transition $(n=18$; Mann-Whitney $U$ test, $-1.67, p=0.095)$. A fatigueonly model would predict no differences between good and poor readers in the consistency of the response over alternating trials. The decreased response consistency among alternating trials observed here suggests that poor readers exhibit trial-by-trial variability of their responses, which impedes how the brain responds to the dynamic elements of speech.

Relationships between reading ability and response consistency do not appear to be mediated by participant factors such as age, socioeconomic status, and attention, as these factors are not correlated with response consistency within the dataset and thus were not included as covariates (formant transition: $r=-0.011$, $p>0.91 ; r=-0.114, p>0.281 ; r=-0.145, p>0.16$, respectively; vowel: $r=-0.010, p>0.92 ; r=-0.037, p>0.728 ; r=$ $-0.151, p>0.14$, respectively). Additionally, boys and girls within each reading group did not differ on response consistency measures in the formant transition (good: Mann-Whitney $U$ test, $-1.33, p>0.193$; average: Mann-Whitney $U$ test, $-0.28, p>$ 0.796; poor: Mann-Whitney $U$ test, $-0.56, p>0.584$ ) or vowel (good: Mann-Whitney $U$ test, $-0.02, p>0.986$; average: Mann-
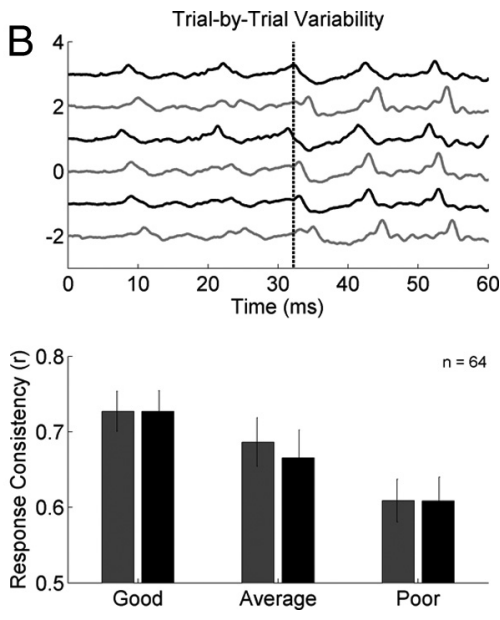

Neural Fatigue
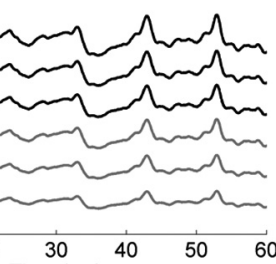

Formant Transition Vowel

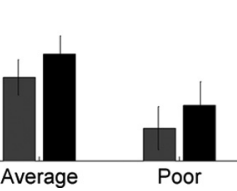

Figure 2. Neural variability in poor readers primarily reflects trial-by-trial inconsistency, not neural fatigue. Two possible mechanisms of response variability are illustrated. $A, 0$ ne mechanism of response variability is fatigue over time. This would be reflected by high variability when comparing responses from the first (black) and second half (gray) of the recording. When gray; $p=0.095$ ). Because our results are identical for the two analysis techniques, they suggest that trial-by-trial variability throughout the recording is the dominant cause of weaker response consistency in poor readers.

Table 1. Group means (SDs) for participant characteristics and auditory brainstem response measures

\begin{tabular}{lrrr}
\hline & Good readers & Average readers & Poor readers \\
\hline Age (months) & $112.0(16.3)$ & $112.9(19.0)$ & $124.7(22.1)$ \\
IQ & $115.4(16.7)$ & $103.5(17.4)$ & $97.4(13.7)$ \\
Attention Rating Scale Percentile & $47.9(29.0)$ & $50.3(32.7)$ & $68.8(24.2)$ \\
Brainstem response consistency $(r)$ & & & \\
$\quad$ First half/second half $(n=100)$ & & & \\
$\quad 7-60 \mathrm{~ms}$ & $0.671(0.13)$ & $0.615(0.14)$ & $0.537(0.16)$ \\
$\quad 60-180 \mathrm{~ms}$ & $0.684(0.14)$ & $0.641(0.14)$ & $0.571(0.18)$ \\
$\quad$ Even events/odd events $(n=64)$ & & & \\
$\quad 7-60 \mathrm{~ms}$ & $0.727(0.11)$ & $0.686(0.14)$ & $0.609(0.16)$ \\
$\quad 60-180 \mathrm{~ms}$ & $0.703(0.11)$ & $0.665(0.16)$ & $0.609(0.16)$ \\
$\quad$ Click-evoked responses $(\mathrm{n}=96)$ & $0.771(0.16)$ & $0.813(0.16)$ & $0.779(0.15)$ \\
$\quad$ Prestimulus amplitude $(\mu \mathrm{V})$ & $0.092(0.02)$ & $0.092(0.02)$ & $0.100(0.02)$ \\
$\quad$ Response amplitude $(\mu \mathrm{V})$ & $0.202(0.06)$ & $0.184(0.03)$ & $0.213(0.09)$ \\
\hline
\end{tabular}

Group differences in neural measures are seen for the consistency of the brainstem response to speech only, and are not mediated by participant characteristics such as age, $\mathrm{IQ}$, and attention.

Whitney $U$ test, $-0.42, p>0.691$; poor: Mann-Whitney $U$ test, $-1.69, p>0.096)$ portions of the response. While these and other factors are known to influence reading ability and auditory brainstem function, the relationships seen here specifically reflect greater neural variability in response to speech in poor readers and are not directly mediated by participant characteristics.

\section{Discussion}

Overall, our results suggest that neural inconsistency in response to sound is a biological mechanism that may contribute to reading impairment. Deficits in auditory task performance may be traced to variability in responses and reaction times that have been documented for children who are poor readers (Roach et al., 2004; Cohen-Mimran and Sapir, 2007; Li et al., 2009; Moore et al., 2010; Van De Voorde et al., 2010). Here we demonstrate that 
children who are poor readers have more variable neural responses to speech, reflecting an inconsistency in the brain's response to sound from trial-to-trial. While we cannot determine whether auditory brainstem variability was present since birth in our participants, it is likely that initial variability in speech sound representations led to weaker phonological development in the preschool years, and weaker phonological development failed to tune the auditory system to selectively represent meaningful speech sound differences as being important. Children with reading difficulties appear to be more sensitive to perceiving and encoding nonmeaningful speech contrasts than their typically developing peers (Bogliotti et al., 2008; Noordenbos et al., 2012), and our current and prior results suggest that they may have additional difficulty in forming robust internal representations of meaningful sounds (Hornickel et al., 2009, 2011), leading to deficits in perception and ultimately in reading. Weaker stability of auditory brainstem representation would also likely lead to less efficient learning of sound statistics and neural adaption to sound repetition, an effect previously linked to speech-in-noise perception, language ability, reading, and musical aptitude in children (Bonte et al., 2007; Chandrasekaran et al., 2009; Evans et al., 2009; Strait et al., 2010). Therefore, we believe that the neural variability seen in the poor readers in our study reflects a combination of "bottom-up" and "top-down" influences, in which neurophysiological impairments and lack of selective attention to meaningful speech sounds interact in a negative feedback loop, likely on a variety of developmental timescales.

Because auditory brainstem responses are generated by the simultaneous and synchronous firing of neurons throughout auditory system nuclei (for review, see Chandrasekaran and Kraus, 2010), a failure in the synchronicity of activity, greater receptor adaptation or fatigue, and/or slower recovery from firing (i.e., longer refractory periods) would result in broader and delayed response peaks and greater interspike variability (Don et al., 1977; Schaette et al., 2005). Additionally, inconsistencies in the response may be due to increased neural "noise"; but increased response variability in poor relative to good readers reported here is not due to greater resting neural activity. Previous studies suggest children with dyslexia have higher internal noise (Sperling et al., 2005), leading to greater difficulty in excluding external noise (Bradlow et al., 2003; Anderson et al., 2010). The present results reveal that the greater internal noise seen for children with dyslexia is independent of general neurophysiological noise and manifests as increased jitter among responses to sound. Additionally, weaker response consistency in poor readers is seen only in response to complex speech-like sounds and not acoustically simple click stimuli, with the greatest deficits seen in response to the formant transition portion of the syllable. Greater neural variability may therefore contribute to deficits in auditory brainstem function that have been reported previously by negatively impacting the fidelity with which neurons represent the most acoustically complex and linguistically meaningful parts of speech sounds.

Here we provide evidence that poor readers have less stable auditory nervous system function than do good readers, a relationship that is not mediated by participant factors such as age, sex, attention, IQ, and socioeconomic status. Although causality cannot be determined, heightened variability in nervous system function may underlie fluctuations in directed attention and impaired speech understanding due to inconsistent encoding. Our results suggest that good readers profit from a stable neural representation of sound, and that children who have inconsistent neural responses are likely at a disadvantage when learning to read. Encouragingly, response consistency can be improved with auditory training, particularly for children with the most variable responses before training (Hornickel et al., 2012a).

\section{References}

Abrams DA, Nicol T, Zecker SG, Kraus N (2006) Auditory brainstem timing predicts cerebral dominance for speech sounds. J Neurosci 26:11131-11137. CrossRef Medline

Anderson S, Skoe E, Chandrasekaran B, Kraus N (2010) Neural timing is linked to speech perception in noise. J Neurosci 30:4922-4926. CrossRef Medline

Banai K, Nicol T, Zecker SG, Kraus N (2005) Brainstem timing: implications for cortical processing and literacy. J Neurosci 25:9850-9857. CrossRef Medline

Banai K, Hornickel J, Skoe E, Nicol T, Zecker S, Kraus N (2009) Reading and subcortical auditory function. Cereb Cortex 19:2699-2707. CrossRef Medline

Basu M, Krishnan A, Weber-Fox C (2010) Brainstem correlates of temporal auditory processing in children with specific language impairment. Dev Sci 13:77-91. CrossRef Medline

Bogliotti C, Serniclaes W, Messaoud-Galusi S, Sprenger-Charolles L (2008) Discrimination of speech sounds by children with dyslexia: comparisons with chronological age and reading level controls. J Exp Child Psychol 101:137-155. CrossRef Medline

Bonte ML, Poelmans H, Blomert L (2007) Deviant neurophysiological responses to phonological regularities in speech in dyslexic children. Neuropsychologia 45:1427-1437. CrossRef Medline

Bradlow AR, Kraus N, Hayes E (2003) Speaking clearly for children with learning disabilities: sentence perception in noise. J Speech Lang Hear Res 46:80-97. CrossRef Medline

Cao F, Bitan T, Chou TL, Burman DD, Booth JR (2006) Deficient orthographic and phonological representations in children with dyslexia revealed by brain activation patterns. J Child Psychol Psychiatry 47: 1041-1050. CrossRef Medline

Chandrasekaran B, Kraus N (2010) The scalp-recorded brainstem response to speech: neural origins. Psychophysiology 47:236-246. CrossRef Medline

Chandrasekaran B, Hornickel J, Skoe E, Nicol T, Kraus N (2009) Contextdependent encoding in the human auditory brainstem relates to hearing speech in noise: implications for developmental dyslexia. Neuron 64:311319. CrossRef Medline

Cohen-Mimran R, Sapir S (2007) Auditory temporal processing deficits in children with reading disabilities. Dyslexia 13:175-192. CrossRef Medline

Don M, Allen AR, Starr A (1977) Effect of click rate on the latency of auditory brain stem responses in humans. Ann Otol Rhinol Laryngol 86:186195. Medline

DuPaul GJ, Power TJ, Anastopoulos AD, Reid R (1998) ADHD rating scale IV. New York: Guilford.

Evans JL, Saffran JR, Robe-Torres K (2009) Statistical learning in children with specific language impairment. J Speech Lang Hear Res 52:321-335. Medline

Facoetti A, Trussardi AN, Ruffino M, Lorusso ML, Cattaneo C, Galli R, Molteni M, Zorzi M (2010) Multisensory spatial attention deficits are predictive of phonological decoding skills in developmental dyslexia. J Cogn Neurosci 22:1011-1025. CrossRef Medline

Friel-Patti S, Finitzo T (1990) Language learning in a prospective study of otitis media with effusion in the first two years of life. J Speech Hear Res 33:188-194. Medline

Gabrieli JD (2009) Dyslexia: a new synergy between education and cognitive neuroscience. Science 325:280-283. CrossRef Medline

Goswami U, Wang HL, Cruz A, Fosker T, Mead N, Huss M (2011) Language-universal sensory deficits in developmental dyslexia: English, Spanish, and Chinese. J Cogn Neurosci 23:325-337. CrossRef Medline

Gou Z, Choudhury N, Benasich AA (2011) Resting frontal gamma power at 16,24 , and 36 months predicts individual differences in language and cognition at 4 and 5 years. Behav Brain Res 220:263-270. CrossRef Medline

Hari R, Renvall H (2001) Impaired processing of rapid stimulus sequences in dyslexia. Trends Cogn Sci 5:525-532. CrossRef Medline

Hornickel J, Skoe E, Nicol T, Zecker S, Kraus N (2009) Subcortical differentiation of stop consonants relates to reading and speech-in-noise perception. Proc Natl Acad Sci U S A 106:13022-13027. CrossRef Medline 
Hornickel J, Chandrasekaran B, Zecker S, Kraus N (2011) Auditory brainstem measures predict reading and speech-in-noise perception in schoolaged children. Behav Brain Res 216:597-605. CrossRef Medline

Hornickel J, Zecker SG, Bradlow AR, Kraus N (2012a) Assistive listening devices drive neuroplasticity in children with dyslexia. Proc Natl Acad Sci U S A 109:16731-16736. CrossRef Medline

Hornickel J, Anderson S, Skoe E, Yi HG, Kraus N (2012b) Subcortical representation of speech fine structure relates to reading ability. Neuroreport 23:6-9. CrossRef Medline

Huss M, Verney JP, Fosker T, Mead N, Goswami U (2011) Music, rhythm, rise time perception and developmental dyslexia: perception of musical meter predicts reading and phonology. Cortex 47:674-689. CrossRef Medline

Klatt DH (1980) Software for a cascade/parallel formant synthesizer. J Acoust Soc Am 67:971-995. CrossRef

Kraus N, McGee TJ, Carrell TD, Zecker SG, Nicol TG, Koch DB (1996) Auditory neurophysiologic responses and discrimination deficits in children with learning problems. Science 273:971-973. CrossRef Medline

Lallier M, Tainturier MJ, Dering B, Donnadieu S, Valdois S, Thierry G (2010) Behavioral and ERP evidence for amodal sluggish attentional shifting in developmental dyslexia. Neuropsychologia 48:4125-4135. CrossRef Medline

Li JJ, Cutting LE, Ryan M, Zilioli M, Denckla MB, Mahone EM (2009) Response variability in rapid automatized naming predicts reading comprehension. J Clin Exp Neuropsychol 31:877-888. CrossRef Medline

Moore DR, Ferguson MA, Edmondson-Jones AM, Ratib S, Riley A (2010) Nature of auditory processing disorder in children. Pediatrics 126:e382-e390. CrossRef Medline

Noordenbos MW, Segers E, Serniclaes W, Mitterer H, Verhoeven L (2012) Neural evidence of allophonic perception in children at risk for dyslexia. Neuropsychologia 50:2010-2017. CrossRef Medline

Pugh KR, Mencl WE, Jenner AR, Katz L, Frost SJ, Lee JR, Shaywitz SE, Shay- witz BA (2001) Neurobiological studies of reading and reading disability. J Commun Disord 34:479-492. CrossRef Medline

Roach NW, Edwards VT, Hogben JH (2004) The tale is in the tail: an alternative hypothesis for psychophysical performance variability in dyslexia. Perception 33:817-830. CrossRef Medline

Saffran JR, Aslin RN, Newport EL (1996) Statistical learning by 8-monthold infants. Science 274:1926-1928. CrossRef Medline

Schaette R, Gollisch T, Herz AV (2005) Spike-train variability of auditory neurons in vivo: dynamic responses follow predictions from constant stimuli. J Neurophysiol 93:3270-3281. CrossRef Medline

Sperling AJ, Lu ZL, Manis FR, Seidenberg MS (2005) Deficits in perceptual noise exclusion in developmental dyslexia. Nat Neurosci 8:862-863. CrossRef Medline

Strait DL, Kraus N, Parbery-Clark A, Ashley R (2010) Musical experience shapes top-down auditory mechanisms: evidence from masking and auditory attention performance. Hear Res 261:22-29. CrossRef Medline

Torgesen JK, Wagner RK, Rashotte CA (1999) Test of Word Reading Efficiency (TOWRE). Austin, TX: Pro-Ed.

Van De Voorde S, Roeyers H, Verté S, Wiersema JR (2010) Working memory, response inhibition, and within-subject variability in children with attention-deficit/hyperactivity disorder or reading disorder. J Clin Exp Neuropsychol 32:366-379. CrossRef Medline

Van Ingelghem M, van Wieringen A, Wouters J, Vandenbussche E, Onghena P, Ghesquière P (2001) Psychophysical evidence for a general temporal processing deficit in children with dyslexia. Neuroreport 12:3603-3607. CrossRef Medline

Wible B, Nicol T, Kraus N (2002) Abnormal neural encoding of repeated speech stimuli in noise in children with learning problems. Clin Neurophysiol 113:485-494. CrossRef Medline

Woerner C, Overstreet K (1999) Wechsler Abbreviated Scale of Intelligence (WASI). San Antonio, TX: The Psychological Corporation.

Ziegler JC, Pech-Georgel C, George F, Lorenzi C (2009) Speech-perceptionin-noise deficits in dyslexia. Dev Sci 12:732-745. CrossRef Medline 